\title{
Hyperglycaemia and apoptosis of microglial cells in human septic shock
}

\author{
Andrea Polito', Jean-Philippe Brouland ${ }^{2}$, Raphael Porcher ${ }^{3}$, Romain Sonneville ${ }^{1,6}$, Shidasp Siami ${ }^{1}$, \\ Robert D Stevens ${ }^{4}$, Céline Guidoux ${ }^{1}$, Virginie Maxime', Geoffroy Lorin de la Grandmaison ${ }^{5}$, Fabrice C Chrétien ${ }^{6}$, \\ Françoise Gray ${ }^{2}$, Djillali Annane ${ }^{1}$ and Tarek Sharshar ${ }^{1 *}$
}

\begin{abstract}
Introduction: The effect of hyperglycaemia on the brain cells of septic shock patients is unknown. The objective of this study was to evaluate the relationship between hyperglycaemia and apoptosis in the brains of septic shock patients.

Methods: In a prospective study of 17 patients who died from septic shock, hippocampal tissue was assessed for neuronal ischaemia, neuronal and microglial apoptosis, neuronal Glucose Transporter (GLUT) 4, endothelial inducible Nitric Oxide Synthase (iNOS), microglial GLUT5 expression, microglial and astrocyte activation. Blood glucose $(\mathrm{BG})$ was recorded five times a day from ICU admission to death. Hyperglycaemia was defined as a BG 200 $\mathrm{mg} / \mathrm{dL} \mathrm{g} / \mathrm{l}$ and the area under the BG curve (AUBGC) $>2 \mathrm{~g} / \mathrm{l}$ was assessed.

Results: Median BG over ICU stay was $2.2 \mathrm{~g} / \mathrm{l}$. Neuronal apoptosis was correlated with endothelial iNOS expression (rho $=0.68, P=0.04$ ), while microglial apoptosis was associated with AUBGC $>2 \mathrm{~g} / \mathrm{l}$ ( $\mathrm{rho}=0.70 ; P=0.002$ ). Neuronal and microglial apoptosis correlated with each other (rho $=0.69, P=0.006$ ), but neither correlated with the duration of septic shock, nor with GLUT4 and 5 expression. Neuronal apoptosis and ischaemia tended to correlate with duration of hypotension.

Conclusions: In patients with septic shock, neuronal apoptosis is rather associated with iNOS expression and microglial apoptosis with hyperglycaemia, possibly because GLUT5 is not downregulated. These data provide a mechanistic basis for understanding the neuroprotective effects of glycemic control.
\end{abstract}

\section{Introduction}

Sepsis and septic shock are associated with hyperglycaemia and peripheral insulin resistance $[1,2]$. Glycemic control strategies are commonly instituted as adjunctive therapeutic measures in critically ill patients, although recent studies have not consistently shown a benefit from intensive insulin therapy [3-6]. One argument supporting blood glucose control is that intensive insulin therapy is associated with a protective effect on the peripheral and central nervous system [7]. While it has been shown that intensive insulin therapy reduces the incidence of critical illness neuromyopathy $[7,8]$ and that hyperglycaemia worsens brain injury in ischemic

\footnotetext{
* Correspondence: tarek.sharshar@rpc.aphp.fr

'General Intensive Care Medicine, Raymond Poincaré Hospital (AP-HP), University of Versailles Saint Quentin en Yvelines, 104 bd R. Poincaré, Garches 92210, France

Full list of author information is available at the end of the article
}

stroke [9-11] and head trauma [12], the effect of hyperglycaemia or insulin on sepsis related brain dysfunction is not well understood. A recent in vitro study showed that hyperglycaemia increased microglial vulnerability to lipopolysaccharide (LPS) mediated toxicity [13], through formation of oxidative free radicals. Interestingly, it has also been shown that experimental sepsis induces oxidative damages in the brain [14]. In a previous neuropathological study, we found that septic shock is associated with neuronal ischaemia, microglial activation and apoptosis as well as neuronal apoptosis, which was statistically correlated with endothelial expression of iNOS [15]. However, the relationships between BG and neuropathological findings have not been thoroughly assessed. The objective of the present study was to address this issue and also to assess whether hyperglycaemia is associated with neuronal or microglial
C Biomed Central

() 2011 Polito et al.; licensee BioMed Central Ltd. This is an open access article distributed under the terms of the Creative Commons Attribution License (http://creativecommons.org/licenses/by/2.0), which permits unrestricted use, distribution, and reproduction in any medium, provided the original work is properly cited. 
apoptosis after adjustment to other pro-apoptotic factors. We also evaluated brain expression of Glucose Transporter (GLUT) proteins given their role in transmembrane glucose transport in neurons and microglial cells during stress conditions [16]. Assessment of the relationships between hyperglycaemia and neuropathological abnormalities might provide insight on the mechanisms of sepsis associated neurological and psycho-cognitive long-term consequences.

\section{Materials and methods Patients}

We investigated consecutive patients who died from septic shock while receiving treatment in the ICU at Raymond Poincaré University Hospital, Garches, France [15]. Exclusion criteria were: age younger than 18 years; pregnancy; evidence of an underlying degenerative neurological disease determined clinically or on post-mortem examination, or any concomitant disease other than infection that might have accounted for shock and death. We obtained informed consent from the patient's closest relatives. The protocol was approved by the Comité Consultatif de Protection des Personnes se Prêtant à la Recherche Biomédicale de Saint Germain en Laye, France.

\section{Data collection}

Demographic characteristics, pre-existing risk factors for vascular disease, and severity of illness using simplified acute physiology score II (SAPS II) [17] and sequential organ failure assessment (SOFA) $[17,18]$ score were routinely recorded. Vital signs were recorded continuously, enabling calculation of duration of shock and cumulative time passed with a mean blood pressure of less than $60 \mathrm{mmHg}$. Standard laboratory tests and relevant microbiological data were recorded daily. All arterial and capillary BG levels measured between admission and death were collected. Hyperglycaemia and hypoglycaemia were considered when BG levels were above $2 \mathrm{~g} /$ $\mathrm{l}$ and $0.4 \mathrm{~g} / \mathrm{l}$, respectively $[5,6,19]$. Then, we assessed the highest and lowest $B G$, highest variation $(\Delta \max )$ in one day in $B G$, mean $B G$, area under the $B G$ curve (AUBGC), and AUBGC above $2 \mathrm{~g} / \mathrm{l}$ (that is, hyperglycaemia). The AUBGC cut-off of $2 \mathrm{~g} / \mathrm{L}$ was chosen because it reflected a compromise between the duration of hyperglycaemia and the value of blood glucose. This cut-off also allows to account for the irregular times intervals between sample collection. We also assessed the percentage of follow-up time in hypoglycaemia and in hyperglycaemia, as well as the proportion of patients who were treated with insulin and who developed hypoglycaemia and hyperglycaemia. We defined prolonged hyperglycaemia as BG values higher than $2 \mathrm{~g} / \mathrm{l}$ more than $50 \%$ of follow-up time (with linear interpolation between two consecutive blood samplings). During the study period (from 1997 to 2001), no specific protocol for the management of hyperglycaemia had been implemented.

\section{Brain sampling}

Brain samples were collected within $12 \mathrm{~h}$ of death. Gross examination of the brain was done after four to six weeks of formalin-fixation on coronal sections of the cerebral hemispheres and horizontal sections of the brain stem and cerebellum. Macroscopic changes were noted, and we selected the hippocampus for microscopic examination, after paraffin embedding. We decided to evaluate changes in the hippocampus as it is highly vulnerable to metabolic insults, hypoxemia and ischaemia $[20,21]$. Sections were stained with haematoxylin and eosin and Bodian silver impregnation combined with Luxol fast blue.

\section{Ischaemia, gliosis and apoptosis}

Histological analysis was performed by one observer (FG) who was blinded to glycemic levels. As previously described [15,22], neurons were described as ischaemic when they presented with shrunken eosinophilic cytoplasm and pyknotic nuclei. Glial reaction (that is, gliosis) was identified as rod-shaped microglial cells and astrocytes with clear nuclei. Astrocyte and microglial activation was assessed by evaluating immunohistochemical expression of glial fibrillary acidic protein (GFAP, Dako, Glostrup, Denmark) and MHC class II antigens (HLA-DR) (Dako), CD68 (Dako). Axonal damage was assessed using immunohistochemistry for Amyloid Precursor Protein A4 (beta-APP) (MAB348, Chemicon, Lyon, France). Tissue expression of GLUT1 (a3536, Dako), GLUT3 (ab41525, Abcam, Cambridge, UK), GLUT4 (ab65976, Abcam) and GLUT5 (ab36057, Abcam), were also assessed as well as that of tumor necrosis factor $\alpha$ (TNF $\alpha)$ (Genzyme, Dako) and inducible NO synthase [23]. We previously found that sepsisassociated expression of TNF $\alpha$ and iNOS involve glial and endothelial cells, respectively [15]. Apoptosis was identified using a caspase 3 monoclonal antibody (Dako), and by in-situ end labelling (ISEL) [24] with use of ApopTag kit (Oncor, Gaithersburg, MD, USA). Intensity of neuronal ischaemia, gliosis, glial activation and apoptosis were graded between 0 and 3, as described elsewhere [15]. Expression of neuronal betaAPP, glial TNF $\alpha$, endothelial iNOS, neuronal GLUT 1, GLUT3, GLUT4 and microglial GLUT5 expression were also graded from 0 to 3 [15]. Because immunostaining of GLUT3 was not satisfactory and that of GLUT1 immunostainings did not vary among patients, we did not assess their statistical correlation with blood glucose level. 


\section{Statistical analyses}

Quantitative and qualitative variables were expressed as median (interquartile range, IQR) and percentage, respectively. Association between continuous variables was assessed by non parametric Spearman correlation coefficient. Adjustment was performed by multiple linear models based on ranks, in accordance to the use of non-parametric rank correlation coefficients. Continuous and categorical variables were compared between groups of patients by Wilcoxon rank-sum test and Fisher's exact test, respectively. Values of $P<0.05$ were considered as indicating statistical significance. All statistical analyses were performed using R 2.6.2 statistical software (The R Foundation for Statistical Computing, Vienna, Austria).

\section{Results}

From 1997 to 2001, 17 patients who died from septic shock were included. Patient characteristics are presented in Table 1. Septic shock had a median duration of four days and was mainly secondary to pneumonia or cellulitis. Four patients had pre-existing diabetes mellitus. Median BG over ICU stay was $2.17 \mathrm{~g} / \mathrm{l}$. Episodes of hyperglycaemia were observed in all patients and hypoglycaemia occurred in five (29\%) patients. Nine (53\%) patients developed prolonged hyperglycaemia and six (35\%) were treated with insulin (with mean BG level of $2.7 \mathrm{~g} / \mathrm{L}$ (1.9 to 3.0)). Macroscopic findings were ischaemia $(\mathrm{n}=12)$, haemorrhage $(\mathrm{n}=9)$ and disseminated abcesses $(\mathrm{n}=3)$. Oedema was observed in only one patient.

In contrast to HLA-DR, expression of microglial CD68 tended to be correlated with AUBGC $>2 \mathrm{~g} / \mathrm{l}$ (rho = $0.44, P=0.08$ ). Intensity of neuronal and microglial apoptosis was correlated with AUBGC $>2 \mathrm{~g} / \mathrm{l}($ rho $=$ $0.53 ; P=0.03$ and rho $=0.70 ; P=0.002$ ) (Table 2, Figure 1). Intensity of neuronal beta-APP expression correlated with AUBGC $>2 \mathrm{~g} / \mathrm{l}(\mathrm{rho}=0.61 ; P=0.03)$ (Figure 2 ). Endothelial iNOS expression was correlated with intensity of neuronal apoptosis ( $\mathrm{rho}=0.68, P=0.005$ ) but not with that of microglial apoptosis (rho $=0.34, P$ $=0.17$ ). The intensities of neuronal and microglial apoptosis were correlated (rho $=0.56, P=0.02$ ). Immunostaining of GLUT3 was not satisfactory. GLUT1 rather stained endothelial cells than neurons and its expression did not vary among patients. Neuronal GLUT4 (Figure 3) and microglial GLUT5 expression (Figure 4) did not correlate with prolonged hyperglycaemia nor with neuronal or microglial apoptosis (Table 3). Expressions of endothelial iNOS and microglial GLUT5 were inversely correlated (rho $=-0.54 ; P=0.03$ ). Neuronal and microglial apoptosis were not correlated with SAPS-II at admission, highest SOFA score, duration of septic shock, or with serum sodium (especially hyponatremia), lowest systolic arterial pressure, $\mathrm{PaO}_{2}$ and $\mathrm{SaO}_{2}$. Intensity of neuronal apoptosis and ischaemia tended to be
Table 1 Patients' characteristics

\begin{tabular}{|c|c|}
\hline & $\begin{array}{c}\text { Whole population } \\
\quad(n=17)\end{array}$ \\
\hline Women (\%) & $6(35)$ \\
\hline Age (years) & 68 (53 to 72$)$ \\
\hline Cerebrovascular risk factors (\%) & $11(65)$ \\
\hline Diabetes (\%) & $4(24)$ \\
\hline Medical admission & $11(65)$ \\
\hline \multicolumn{2}{|l|}{ Site of infection } \\
\hline Lung only (\%) & $9(53)$ \\
\hline Abdominoperitoneal only (\%) & 0 \\
\hline Urinary tract only (\%) & 0 \\
\hline Cellulitis only (\%) & $5(29)$ \\
\hline$>1$ site & $5(18)$ \\
\hline Unknown & 0 \\
\hline \multicolumn{2}{|l|}{ Positive culture at any site (\%) } \\
\hline Gram-positive only (\%) & $4(24)$ \\
\hline Gram-negative only (\%) & $6(35)$ \\
\hline Fungus only (\%) & 0 \\
\hline Mixed (\%) & $7(411)$ \\
\hline Positive blood culture (\%) & $4(24)$ \\
\hline SAPS-II at admission & 43 (30 to 58$)$ \\
\hline Highest OSF score during ICU stay & $4(4$ to 5$)$ \\
\hline Duration of septic shock (days) & $4(2$ to 10$)$ \\
\hline Cumulative time spent with MAP $<60 \mathrm{~mm} \mathrm{Hg}$ (h) & $11(4$ to 25$)$ \\
\hline Lowest SAP (mm Hg) & 57 (33 to 66) \\
\hline Lowest $\mathrm{PaO}_{2}(\mathrm{kPa})$ & $8.1(6.1$ to 9.0$)$ \\
\hline Lowest $\mathrm{SaO}_{2}(\%)$ & 85 (73 to 90$)$ \\
\hline Highest blood sodium level (mmol/L) & 139 (135 to 149$)$ \\
\hline Lowest blood sodium level (mmol/L) & $132(128$ to 137$)$ \\
\hline \multicolumn{2}{|l|}{ Blood glucose level } \\
\hline Lowest BG (gr/l) & $0.6(0.3$ to 1.1$)$ \\
\hline Highest BG (gr/l) & 3.5 (3.3 to 5.4$)$ \\
\hline$\Delta \max B G(g r / l)$ & 3.4 (2.1 to 4.8$)$ \\
\hline Mean BG (gr/l) & 2.2 (1.4 to 2.8$)$ \\
\hline Patients with hypoglycaemia (\%) & $5(29)$ \\
\hline Patients with hyperglycaemia (\%) & $15(88)$ \\
\hline Patients with prolonged hyperglycaemia (\%) & $9(53)$ \\
\hline Patients treated with insulin (\%) & $6(35)$ \\
\hline Neuronal apoptosis & $1.0(1.0$ to 2.0$)$ \\
\hline Microglial apoptosis & $1.0(1.0$ to 1.5$)$ \\
\hline GFAP expression & $2.0(2.0$ to 3.0$)$ \\
\hline HLA-DR expression & $1.0(1.0$ to 2.0$)$ \\
\hline CD68 expression & $1.0(0.5$ to 1.5$)$ \\
\hline Glial TNF- $\alpha$ expression & $1.0(0$ to 1.0$)$ \\
\hline iNOS expression & $1.0(1.0$ to 1.0$)$ \\
\hline Neuronal GLUT4 & 1.5 (1.0 to 2.0$)$ \\
\hline Microglial GLUT5 & $1.0(0.5$ to 1.0$)$ \\
\hline CD68 & 1.5 (1.0 to 2.0$)$ \\
\hline Beta-APP & 1.0 (1.0 to 1.5$)$ \\
\hline
\end{tabular}

Beta APP, beta-amyloid precursor protein; BG, blood glucose; CD68, Cluster of Differentiation; GFAP, Glial Fibrillary Acid Protein; GLUT, glucose transporter; HLA-DR, Major Histocompatibility Complex Class II cell surface receptor; ICU, intensive care unit; iNOS, inducible Nitric Oxide Synthase; MAP, mean arterial pressure; OSF, organ systemic failure; $\mathrm{PaO}_{2}$, partial pressure of oxygen in arterial blood; SAP, systolic arterial pressure; SAPS-II, simplified acute physiology score; $\mathrm{SaO}_{2}$, saturation of oxygen in arterial blood; TNF $\alpha$, tumor necrosis factor alpha. 
Table 2 Association of the area under the BG curve above $2 \mathrm{~g} / \mathrm{l}$ with clinical characteristics and neuropathological findings

\begin{tabular}{lcc}
\hline & Spearman $\boldsymbol{\rho}(\mathbf{9 5} \% \mathrm{Cl})$ & $\boldsymbol{P}$ \\
\hline SAPS-II at admission & $0.34(-0.17$ to 0.71$)$ & 0.18 \\
Knauss & $-0.21(-0.63$ to 0.30$)$ & 0.43 \\
McCabe & $0.05(-0.44$ to 0.52$)$ & 0.85 \\
Neuropathological findings & & \\
Neuronal ischaemia & $0.05(-0.43$ to 0.53$)$ & 0.82 \\
Gliosis & $0.15(-0.36$ to 0.59$)$ & 0.57 \\
GFAP expression & $0.11(-0.39$ to 0.56$)$ & 0.67 \\
HLA-DR expression & $0.06(-0.43$ to 0.53$)$ & 0.81 \\
CD68 expression & $0.44(-0.05$ to 0.76$)$ & 0.08 \\
Beta-APP expression & $0.61(0.06$ to 0.88$)$ & 0.03 \\
Neuronal apoptosis & $0.53(0.07$ to 0.81$)$ & 0.028 \\
Microglial apoptosis & $0.70(0.33$ to 0.88$)$ & 0.002 \\
Glial TNF $\alpha$ expression & $-0.04(-0.51$ to 0.45$)$ & 0.86 \\
Endothelial iNOS expression & $0.04(-0.45$ to 0.51$)$ & 0.87 \\
\hline
\end{tabular}

Each neuropathological finding was score from 0 to 3 (see methods). betaAPP, beta-amyloid precursor protein; CD68, Cluster of Differentiation; GFAP glial fibrillary acidic protein; HLA-DR, Major Histocompatibility Complex Class II cell surface receptor; iNOS, inducible Nitric Oxide Synthase; TNF $\alpha$, tumor necrosis factor alpha.

correlated with cumulative time of hypotension (rho = $0.45, P=0.06$ and rho $=0.38, P=0.11$ ).

\section{Discussion}

In patients dying of septic shock, hyperglycaemia was associated with microglial apoptosis while neuronal apoptosis was preferentially associated with endothelial iNOS expression. We also found that hyperglycaemia

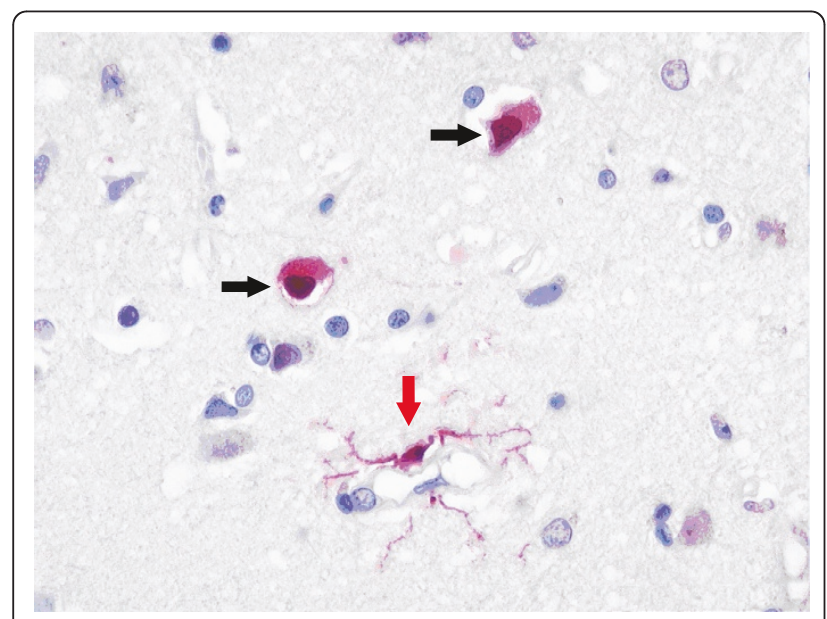

Figure 1 Neuronal and microglial apoptosis in cerebral amygdale. Case 7359, Cerebral amygdala. The back arrows show two apoptotic neurons with darkly stained nucleus. The red arrow shows an apoptotic microglial cell with a dark nucleus. The cytoplasm of the apoptotic cells is also stained corresponding to disintegration of nuclear chromatin into apoptotic bodies. (ISEL $\times 800$ ).

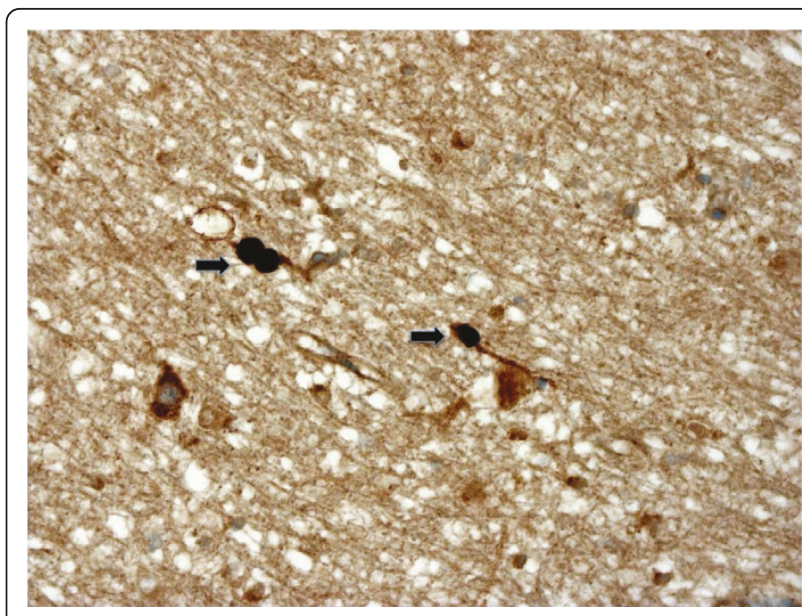

Figure 2 Axonal damage in the hippocampal white matter. Cortico-subcortical junction in the hippocampus. Black arrows show axonal swellings in the white matter. These represent the accumulation of the precursor of the beta-amyloid protein due to alteration of the axonal flow. (APP imunostaining ABC/peroxidase/ $D A B \times 25)$.

tended to be correlated with CD68 expression, which is a marker of microglial activation. The postulated relationship between hyperglycaemia and microglial cell apoptosis was supported by its absence of statistical correlation with hypotension, hypoxemia or hypernatremia, while it is known that hippocampus is highly vulnerable to these factors. We also found that neuronal GLUT4 and microglial GLUT5 expressions were not correlated with blood glucose level, suggesting impaired downregulation.

These results are consistent with several experimental studies. Discrepancy between microglial CD68 and HLA-DR immunostaining has been previously observed

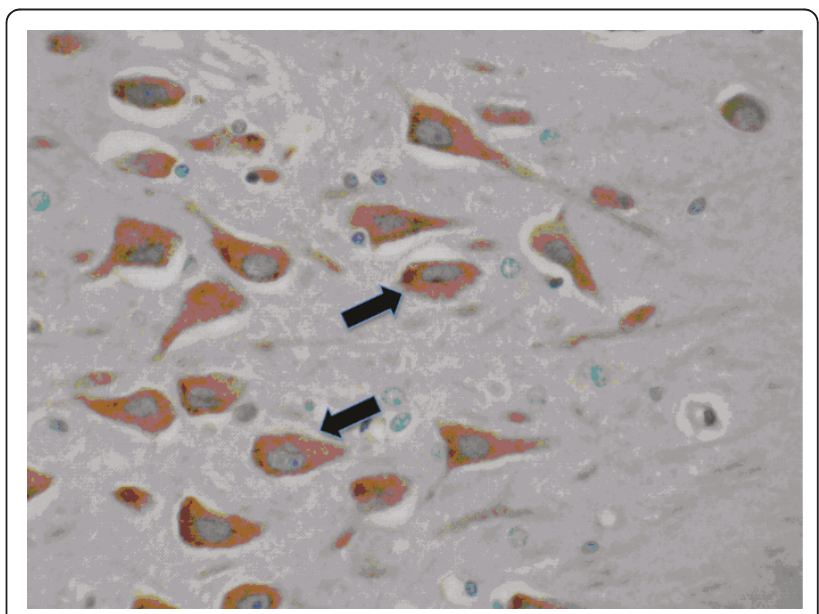

Figure 3 Hippocampal expression of GLUT4. Hippocampal interneurons in CA1 and CA4 exhibit a homogeneous cytoplasmic staining (arrow) with GLUT4 antibody (ABC/peroxidase/DAB, x40). 


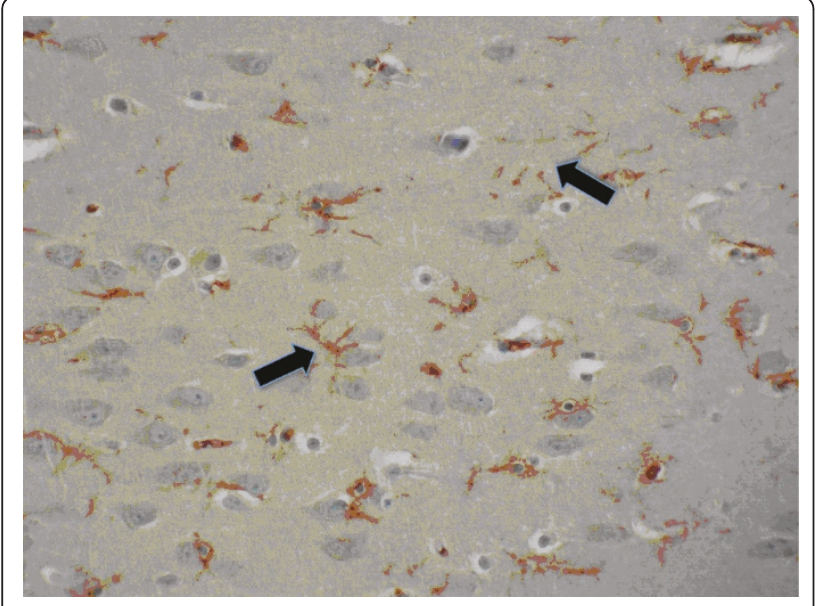

Figure 4 Hippocampal expression of GLUT5. In hippocampal interneurons (CA1 and CA4), microglial cells are strongly stained (arrows) whereas neurons are not labelled with GLUT5 antibody (ABC/peroxidase/DAB, x25).

[25] and was ascribed to the fact that CD68 is a better marker of activated microglia. Nitric oxide has been extensively documented as pro-apoptotic factor, notably in experimental sepsis [26-28]. In experimental models of cerebral trauma or ischaemia, hyperglycaemia has been linked to neuronal and glial cell injury through various mechanisms including mitochondrial dysfunction, oxidative stress, inflammation and excitotoxicity [29]. Although the similar mechanisms have been implicated in sepsis associated encephalopathy, the potential contribution of hyperglycaemia had not been elucidated. It was recently shown that high glucose and LPS synergistically induce microglial apoptosis by enhancing formation of oxidative free radicals [13]. Interestingly, the statistical correlation between neuronal and microglial apoptosis suggest that they are interdependent phenomenon. It is established that neuronal function and survival is intimately linked to both astroglial and microglial cells [30]. Therefore, one may speculate that hyperglycaemia induces microglial death that, synergistically with endothelial iNOS, induces neuronal apoptosis, suggesting a mechanistic sequence to account for sepsis associated brain dysfunction. This model takes into account the inflammatory [23] and metabolic (hyperglycaemia) pathways that are a major pathophysiological process and disturbance of septic shock, respectively. The correlation between hyperglycaemia and axonal betaAPP expression is consistent with that reported in experimental brain ischaemia [31]. It suggests also another scenario in which hyperglycaemia would first induce axonal injury, then secondary degeneration of microglia [31]. Interestingly, this finding proposes a new pathophysiological mechanism for the long-term cognitive decline in septic patients [32].

The present study is the first to describe the neuropathological consequences of hyperglycaemia in patients who had died from septic shock. However, our study has several limitations. First, one may argue that apoptosis was rather a post-mortem phenomenon. Although this possibility cannot be ruled out, we have previously shown that cell death did not correlate with time to brain sampling [15]. Second, since BG levels were not assessed continuously, it is likely that discrete hypoglycaemic or hyperglycaemic events were not detected. However, the rate of BG assessment was not different between patients with and without hyperglycaemia or prolonged hyperglycaemia. Third, it has been shown that the capillary test does not provide an accurate measurement of BG, notably overestimating it [33]. However, despite this flaw, capillary meter is used both in clinical trials and in routine for titrating insulin therapy. It has to be noted that microglial apoptosis was also correlated with median BG. Fourth, we have limited our investigation to the hippocampus as it is highly sensitive to hemodynamic, hypoxic or metabolic insults but also involved in ICU associated delirium pathophysiology $[34,35]$. The impact of neuronal and microglial apoptosis on hippocampal function cannot be obviously inferred from these simple neuropathological observations. It would be of interest to determine experimentally if hyperglycaemia is associated with alterations in hippocampal electrophysiological function and with cognitive impairments mediated by hippocampal structures. It has been reported that high glucose level is associated with occurrence of delirium in ICU patients [36]. Conversely, it has been shown that infusion of glucose is a memory enhancer in septic rats, suggesting that glucose tight control, or at least hypoglicaemia, may affect hippocampal functions [37].

While we have demonstrated an association between hyperglycaemia and cell death in the brains of septic shock patients, these data do not allow us to make any

Table 3 Association of neuronal GLUT4 and microglial GLUT5 expression with glycaemia and cell apoptosis

\begin{tabular}{lcccc}
\hline Spearman $\boldsymbol{\rho}(\mathbf{9 5 \%} \mathrm{Cl})$ & Neuronal GLUT4 expression & $\boldsymbol{P}$ & Microglial GLUT5 expression & $\boldsymbol{P}$ \\
\hline Area under the BG curve $>2 \mathrm{~g} / \mathrm{l}$ & $-0.006(-0.49$ to 0.48$)$ & 0.98 & $0.03(-0.46$ to 0.50$)$ & 0.91 \\
Neuronal apoptosis & $-0.29(-0.68$ to 0.22$)$ & 0.25 & $-0.40(-0.74$ to 0.10$)$ & 0.11 \\
Microglial apoptosis & $-0.002(-0.48$ to 0.48$)$ & 0.99 & $-0.25(-0.65$ to 0.26$)$ & 0.33 \\
\hline
\end{tabular}

Each neuropathological finding was score from 0 to 3 (see methods). BG, blood glucose; GLUT, glucose transporter. 
definitive conclusions on hyperglycaemia as a causative mechanism for cell death. Indeed, statistical correlations between ante-mortem variables and post-mortem findings do not prove a causal relationship. Demonstration of such a link would require a more detailed investigation of how glucose levels affect microglial cellular and molecular function and the demonstration that glycemic control reduces microglial apoptosis. Only experimental studies could reasonably address these issues. Indeed, post-mortem examination does not yield insight into the proximal processes that precede apoptosis in humans. This may explain that hyperglycaemia tended to be correlated with microglial activation (reflected by CD68 expression), which is prior to apoptosis. Assessment of neuropathological effect of BG control would require brain sampling in patients who had died from septic shock and who had or not been treated with insulin therapy: a task not so easily achievable. Our neuropathological samples were obtained before the widespread implementation of glycemic control with intensive insulin therapy in many critical care units. This is illustrated by the fact that insulin was administered in a small proportion of patients and was not targeted to normoglycaemia. These observations prevented us from assessing the neuropathological effect of insulin. Moreover, anticipating a neurological benefit from insulin therapy is premature. First of all, even if microglial cells play a major role in host defence of the brain, and are involved in neuroinflammatory and neurodegenerative processes, their implication in sepsis related brain dysfunction is not demonstrated [38]. It is unknown whether microglial apoptosis is an adaptive, negligible or deleterious phenomenon. Unlike the situation in neurons, interpretation of positive ISEL staining in glial and microglial cells is not straightforward. As ISEL is not absolutely specific for double-stranded DNA breaks and can also detect single-stranded breaks as observed in cell multiplication [39], positive staining may also reflect cell proliferation. On the other hand, Petito and Roberts [40] suggested that apoptotic death of reactive astrocytes might be a physiological mechanism whereby the brain removes an excess number of astrocytes that have proliferated after certain types of brain injury. This can also apply for microglia [41]. Second, cerebral glucose metabolism is highly complex and its disturbances in sepsis insufficiently elucidated. Therefore, neuronal sensitivity to hypoglycaemia and hyperglycaemia might be deeply changed in sepsis, making the effect of insulin on neuronal metabolism unpredictable. We have found that neuronal GLUT4 and microglial GLUT5 expression were neither correlated with blood glucose levels or cell apoptosis. This does not rule out that glucose transporters are involved in cell death process. For instance, it has been experimentally shown that GLUT5 is implicated in hyperglycaemia-related microglial cell death [13]. Furthermore, one may have expected that glucose transporter expression would have been inversely proportionate to blood glucose level $[40,42,43]$. Therefore, it is conceivable that its absence of downregulation might have increased intracellular glucose concentration and, thereby, its toxicity. We acknowledge that absence of correlation between microglial apoptosis and GLUT expression does not rule out an alteration of GLUT functioning, which in future studies could be indirectly evaluated by measuring intracellular glucose load and protein glycation. Additionally, it is biologically plausible that hypoglycaemia potentially is far more harmful for the brain than hyperglycaemia. It will be worthwhile to assess the neuropathological correlates of hypoglycaemia in patients who had died from septic shock. This would require a greater proportion of patients who had developed hypoglycaemia than that observed in the present study. It is interesting to note that iNOS has been shown to decrease cerebral GLUT1 expression [44]. One may argue that the slight GLUT1 immunostaining of neurons reflects a downregulation. Although expression of GLUT3 could not have been assessed for technical reasons, it has to be noted that alteration of GLUT3 cannot account for the relationship between hyperglycaemia and apoptosis microglial cells as it is not expressed by these cells.

The present study suggests a similar effect on microglial GLUT5 expression. Other mechanisms could be involved, especially perivascular edema that can compromise substrate and oxygen delivery. Although we have not specifically assessed this mechanism, it is established that the BBB is altered in experimental sepsis but also in septic shock patients [45].

Despite these limitations, our study suggests that hyperglycaemia may contribute to the complex web of abnormal signalling, which causes sepsis associated brain dysfunction. Future studies should investigate the mechanisms of hyperglycaemia related microglial apoptosis, particularly the impaired downregulation of GLUT, and assess the neuropathological as well as neurological effects of BG control by insulin therapy.

\section{Conclusions}

It appears likely that hemodynamic, inflammatory and metabolic factors contribute to brain cell dysfunction and death during septic shock, and may account for sepsis associated brain dysfunction, which is associated with increased mortality [46]. More research is needed to understand the pathogenic significance of these factors and how they may be modulated to therapeutic ends. 


\section{Key messages}

- In septic shock patients microglia is strongly activated.

- Hemodynamic, inflammatory and metabolic factors contribute to brain cell dysfunction and death during septic shock.

- Hyperglycaemia is associated with microglial apoptosis while neuronal apoptosis is preferentially associated with endothelial iNOS expression.

- Hyperglycaemia may contribute to the complex web of abnormal signaling which causes sepsis associated brain dysfunction.

\begin{abstract}
Abbreviations
iNOS: inducible Nitric Oxide Synthase; AUBGC: area under the BG curve; Beta-APP: amyloid precursor protein A4; BG: blood glucose; GLUT: glucose transporter; IQR: interquartile range; ISEL: in-situ end labelling; LPS: lipopolysaccharide; SAPS II: Simplified Acute Physiologic Score II; SOFA: Sequential Organ Failure Assessment; TNF-a: tumor necrosis factor a.
\end{abstract}

\begin{abstract}
Author details
'General Intensive Care Medicine, Raymond Poincaré Hospital (AP-HP), University of Versailles Saint Quentin en Yvelines, 104 bd R. Poincaré, Garches 92210, France. ²Department of Pathology, Lariboisière Hospital (APHP), University Denis Diderot-Paris 7, 2 rue Ambroise Paré, Paris 75010, France. ${ }^{3}$ Departement of Biostatistic and Medical Informatics, Saint-Louis Hospital (APHP), University Denis Diderot-Paris 7, 47-83, boulevard de I'Hôpital, Paris 75010, France. ${ }^{4}$ Department of Anesthesiology and Critical Care Medicine, Johns Hopkins University School of Medicine, 600 North Wolfe Street, Baltimore, MD 21287, USA. ${ }^{5}$ Department of Pathology, Raymond Poincaré Hospital (AP-HP), University of Versailles Saint Quentin en Yvelines, 104 bd R. Poincaré, Garches 92210, France. ${ }^{6}$ HISTO, Human Histopathology and Animal Models; Institut Pasteur; Département Infection et Epidémiologie, 25 rue du Dr Roux, 75015 Paris.
\end{abstract}

\section{Authors' contributions}

AP conceived the study, acquired data and wrote the manuscript. JPB helped in interpretation of the data and in drafting the manuscript. RP participated in the design of the study, performed the statistical analysis and helped to draft the manuscript. RS helped to draft the manuscript. SS helped in acquisition of data and revising the manuscript, while RDS also helped to revise the manuscript. CG, FC, FG, DA and VM helped to draft the manuscript. GLG helped in acquisition and interpretation of data. TS conceived the study, participated in the design of the study and helped to draft the manuscript. All the authors read and approved the final manuscript.

\section{Competing interests}

The authors declare that they have no competing interests.

Received: 15 February 2011 Revised: 3 April 2011

Accepted: 25 May 2011 Published: 25 May 2011

\section{References}

1. Brunkhorst FM, Engel C, Bloos F, Meier-Hellmann A, Ragaller M, Weiler N, Moerer O, Gruendling M, Oppert M, Grond S, Olthoff D, Jaschinski U, John S, Rossaint R, Welte T, Schaefer M, Kern P, Kuhnt E, Kiehntopf M, Hartog C, Natanson C, Loeffler M, Reinhart K, German Competence Network Sepsis (SepNet): Intensive insulin therapy and pentastarch resuscitation in severe sepsis. N Engl J Med 2008, 358:125-139.

2. Van den Berghe G: How does blood glucose control with insulin save lives in intensive care? J Clin Invest 2004, 114:1187-1195.

3. Dellinger RP, Levy MM, Carlet JM, Bion J, Parker MM, Jaeschke R, Reinhart K, Angus DC, Brun-Buisson C, Beale R, Calandra T, Dhainaut JF, Gerlach H, Harvey M, Marini JJ, Marshall J, Ranieri M, Ramsay G, Sevransky J, Thompson BT, Townsend S, Vender JS, Zimmerman JL, Vincent JL, et al:
Surviving Sepsis Campaign: international guidelines for management of severe sepsis and septic shock: 2008. Crit Care Med 2008, 36:296-327.

4. Langouche L, Vanhorebeek I, Van den Berghe G: Therapy insight: the effect of tight glycemic control in acute illness. Nat Clin Pract Endocrinol Metab 2007, 3:270-278.

5. Van den Berghe G, Wilmer A, Hermans G, Meersseman W, Wouters PJ, Milants I, Van Wijngaerden E, Bobbaers H, Bouillon R: Intensive insulin therapy in the medical ICU. N Engl J Med 2006, 354:449-461.

6. Van den Berghe $G$, Wouters $P$, Weekers F, Verwaest $C$, Bruyninckx F, Schetz M, Vlasselaers D, Ferdinande P, Lauwers P, Bouillon R: Intensive insulin therapy in the critically ill patients. N Engl J Med 2001, 345:1359-1367.

7. Van den Berghe G, Schoonheydt K, Becx P, Bruyninckx F, Wouters PJ: Insulin therapy protects the central and peripheral nervous system of intensive care patients. Neurology 2005, 64:1348-1353.

8. Hermans G, Wilmer A, Meersseman W, Milants I, Wouters PJ, Bobbaers H, Bruyninckx F, Van den Berghe G: Impact of intensive insulin therapy on neuromuscular complications and ventilator dependency in the medical intensive care unit. Am J Respir Crit Care Med 2007, 175:480-489.

9. Bhalla A, Tilling K, Kolominsky-Rabas P, Heuschmann P, Megherbi SE, Czlonkowska A, Kobayashi A, Mendel T, Giroud M, Rudd A, Wolfe C: Variation in the management of acute physiological parameters after ischaemic stroke: a European perspective. Eur J Neurol 2003, 10:25-33.

10. Capes SE, Hunt D, Malmberg K, Pathak P, Gerstein HC: Stress hyperglycemia and prognosis of stroke in nondiabetic and diabetic patients: a systematic overview. Stroke 2001, 32:2426-2432.

11. Yong M, Kaste M: Dynamic of hyperglycemia as a predictor of stroke outcome in the ECASS-II trial. Stroke 2008, 39:2749-2755.

12. Wahl WL, Taddonio M, Maggio PM, Arbabi S, Hemmila MR: Mean glucose values predict trauma patient mortality. J Trauma 2008, 65:42-47, discussion 47-48.

13. Wang JY, Yang JM, Wang JY, Tao PL, Yang SN: Synergistic apoptosis induced by bacterial endotoxin lipopolysaccharide and high glucose in rat microglia. Neurosci Lett 2001, 304:177-180.

14. Barichello T, Fortunato JJ, Vitali AM, Feier G, Reinke A, Moreira JC, Quevedo J, Dal-Pizzol F: Oxidative variables in the rat brain after sepsis induced by cecal ligation and perforation. Crit Care Med 2006, 34:886-889.

15. Sharshar T, Gray F, Lorin de la Grandmaison G, Hopkinson NS, Ross E, Dorandeu A, Orlikowski D, Raphael JC, Gajdos P, Annane D: Apoptosis of neurons in cardiovascular autonomic centres triggered by inducible nitric oxide synthase after death from septic shock. Lancet 2003, 362:1799-1805.

16. Douard V, Ferraris RP: Regulation of the fructose transporter GLUT5 in health and disease. Am J Physiol Endocrinol Metab 2008, 295:E227-237.

17. Le Gall JR, Lemeshow S, Saulnier F: A new Simplified Acute Physiology Score (SAPS II) based on a European/North American multicenter study. JAMA 1993, 270:2957-2963.

18. Vincent $\mathrm{J}$, Moreno R, Takala J, Willatts S, De Mendonca A, Bruining $\mathrm{H}$, Reinhart CK, Suter PM, Thijs LG: The SOFA (Sepsis-related Organ Failure Assessment) score to describe organ dysfunction/failure. On behalf of the Working Group on Sepsis-Related Problems of the European Society of Intensive Care Medicine. Intensive Care Med 1996, 22:707-710.

19. Van den Berghe G: First do no harm ... hypoglycemia or hyperglycemia? Crit Care Med 2006, 34:2843-2844.

20. Nikonenko AG, Radenovic L, Andjus PR, Skibo GG: Structural features of ischemic damage in the hippocampus. Anat Rec (Hoboken) 2009, 292:1914-1921.

21. Strokin M, Chechneva O, Reymann KG, Reiser G: Neuroprotection of rat hippocampal slices exposed to oxygen-glucose deprivation by enrichment with docosahexaenoic acid and by inhibition of hydrolysis of docosahexaenoic acid-containing phospholipids by calcium independent phospholipase A2. Neuroscience 2006, 140:547-553.

22. Poirier GF, Escourolle R: Manual of Basic Neuropathology. 3 edition. Philadelphia, PA: WB Saunders Company; 1990.

23. Morrison RS, Kinoshita Y, Johnson MD, Guo W, Garden GA: p53-dependent cell death signaling in neurons. Neurochem Res 2003, 28:15-27.

24. Freyer D, Manz R, Ziegenhorn A, Weih M, Angstwurm K, Docke WD, Meisel A, Schumann RR, Schonfelder G, Dirnagl U, Weber JR: Cerebral endothelial cells release TNF-alpha after stimulation with cell walls of Streptococcus pneumoniae and regulate inducible nitric oxide synthase 
and ICAM-1 expression via autocrine loops. J Immunol 1999, 163:4308-4314.

25. Lemstra AW, Groen in't Woud JC, Hoozemans JJ, van Haastert ES, Rozemuller AJ, Eikelenboom P, van Gool WA: Microglia activation in sepsis: a case-control study. J Neuroinflammation 2007, 4:4.

26. Hara MR, Snyder SH: Cell signaling and neuronal death. Annu Rev Pharmacol Toxicol 2007, 47:117-141.

27. Love S: Oxidative stress in brain ischemia. Brain Pathol 1999, 9:119-131.

28. Sastry PS, Rao KS: Apoptosis and the nervous system. J Neurochem 2000, 74:1-20.

29. Garg R, Chaudhuri A, Munschauer F, Dandona P: Hyperglycemia, insulin, and acute ischemic stroke: a mechanistic justification for a trial of insulin infusion therapy. Stroke 2006, 37:267-273.

30. Bessis A, Bechade C, Bernard D, Roumier A: Microglial control of neuronal death and synaptic properties. Glia 2007, 55:233-238.

31. Lin B, Ginsberg MD, Busto R: Hyperglycemic but not normoglycemic global ischemia induces marked early intraneuronal expression of betaamyloid precursor protein. Brain Res 2001, 888:107-116.

32. Iwashyna TJ, Ely EW, Smith DM, Langa KM: Long-term cognitive impairment and functional disability among survivors of severe sepsis. JAMA 2010, 304:1787-1794.

33. Kanji S, Buffie J, Hutton B, Bunting PS, Singh A, McDonald K, Fergusson D, Mclntyre LA, Hebert PC: Reliability of point-of-care testing for glucose measurement in critically ill adults. Crit Care Med 2005, 33:2778-2785.

34. Fricchione GL, Nejad SH, Esses JA, Cummings TJ Jr, Querques J, Cassem NH, Murray GB: Postoperative delirium. Am J Psychiatry 2008, 165:803-812.

35. Miczek KA, Covington HE, Nikulina EM Jr, Hammer RP: Aggression and defeat: persistent effects on cocaine self-administration and gene expression in peptidergic and aminergic mesocorticolimbic circuits. Neurosci Biobehav Rev 2004, 27:787-802.

36. Heymann A, Sander M, Krahne D, Deja M, Weber-Carstens S, MacGuill M, Kastrup M, Wernecke KD, Nachtigall I, Spies CD: Hyperactive delirium and blood glucose control in critically ill patients. J Int Med Res 2007, 35:666-677.

37. Tuon L, Comim CM, Petronilho F, Barichello T, Izquierdo I, Quevedo J, DalPizzol F: Memory-enhancing treatments reverse the impairment of inhibitory avoidance retention in sepsis-surviving rats. Crit Care 2008, 12: R133.

38. Siami S, Annane D, Sharshar T: The encephalopathy in sepsis. Crit Care Clin 2008, 24:67-82, viii.

39. Ansari B, Coates PJ, Greenstein BD, Hall PA: In situ end-labelling detects DNA strand breaks in apoptosis and other physiological and pathological states. J Pathol 1993, 170:1-8.

40. Petito CK, Roberts B: Effect of postmortem interval on in situ endlabeling of DNA oligonucleosomes. J Neuropathol Exp Neurol 1995, 54:761-765.

41. Gray F, Chretien F, Adle-Biassette H, Dorandeu A, Ereau T, Delisle MB, Kopp N, Ironside JW, Vital C: Neuronal apoptosis in Creutzfeldt-Jakob disease. I Neuropathol Exp Neurol 1999, 58:321-328.

42. Duelli R, Maurer MH, Staudt R, Heiland S, Duembgen L, Kuschinsky W: Increased cerebral glucose utilization and decreased glucose transporter Glut1 during chronic hyperglycemia in rat brain. Brain Res 2000, 858:338-347.

43. Koranyi L, Bourey RE, James D, Mueckler M, Fiedorek FT Jr, Permutt MA: Glucose transporter gene expression in rat brain: Pretranslational changes associated with chronic insulin-induced hypoglycemia, fasting, and diabetes. Mol Cell Neurosci 1991, 2:244-252.

44. Takemori $\mathrm{K}$, Ito $\mathrm{H}$, Suzuki T: Effects of inducible nitric oxide synthase inhibition on cerebral edema in severe hypertension. Acta Neurochir Suppl 2000, 76:335-338.

45. Sharshar T, Carlier R, Bernard F, Guidoux C, Brouland JP, Nardi O, Lorin de la Grandmaison G, Aboab J, Gray F, Menon D, Annane D: Brain lesions in septic shock: a magnetic resonance imaging study. Intensive Care Med 2007, 33:798-806.

46. Eidelman LA, Putterman D, Putterman C, Sprung CL: The spectrum of septic encephalopathy. Definitions, etiologies, and mortalities. JAMA 1996, 275:470-473.

doi:10.1186/cc10244

Cite this article as: Polito et al: Hyperglycaemia and apoptosis of microglial cells in human septic shock. Critical Care 2011 15:R131.

\section{Submit your next manuscript to BioMed Central and take full advantage of:}

- Convenient online submission

- Thorough peer review

- No space constraints or color figure charges

- Immediate publication on acceptance

- Inclusion in PubMed, CAS, Scopus and Google Scholar

- Research which is freely available for redistribution 